\title{
Anti-Denatured Collagen Monoclonal Antibody TRC093
}

National Cancer Institute

\section{Source}

National Cancer Institute. Anti-Denatured Collagen Monoclonal Antibody TRC093. NCI

Thesaurus. Code C71749.

\begin{abstract}
A humanized, affinity-matured IgG1k antibody directed against denatured collagens (I-IV) with potential antiangiogenic and antineoplastic activities. Anti-denatured collagen recombinant monoclonal antibody TRC093 binds to multiple epitopes on denatured collagens, inhibiting proteolytic collagen-mediated signaling in the extracellular matrix (ECM) that is important to tumor angiogenesis, tumor growth, and metastasis. The epitopes on denatured collagen bound by this antibody are considered cryptic because, in vivo, they are accessible only on the subendothelial basement membrane of tumors or in normal tissues undergoing neovascularization.
\end{abstract}

